\title{
A Necessidade de Ações Articuladas na Cultura e Extensão
}

The Need for Jointed Actions in Culture and Extension

RESUMO

O Regimento de Cultura e Extensão Universitária regulamenta as atividades de cultura e extensão da Universidade de São Paulo, entendidas, neste contexto, como um processo que articula o ensino e a pesquisa para viabilizar a interação transformadora entre a universidade e a sociedade. Nesse sentido, esta ação enriquece o processo pedagógico, favorece a socialização do saber acadêmico e estabelece uma dinâmica que contribui para a participação da comunidade na vida acadêmica. A proposição de tal documento se deve à importância dos trabalhos desenvolvidos nesta área pela Universidade de São Paulo e também pela necessidade de rever suas diretrizes e conceitos. Dessa maneira, o regimento procura definir as atividades de cultura e extensão universitárias previstas no Estatuto e no Regimento Geral da USP, bem como estabelecer critérios de avaliação para esta ação. Com isso, visa também promover a valorização de tais atividades na avaliação de docentes, alunos e funcionários. Para atingir os almejados fins, é mister uma articulação indissociável entre o ensino, pesquisa e as atividades de extensão e cultura produzidos na academia, bem como a exteriorização dos resultados em prol de benefícios para a sociedade.

Palavras-chave: Cultura. Extensão Universitária. Ações Articuladas.

\section{ABSTRACT}

The Culture and Extension Regiment regulates the activities of culture and extension at University of São Paulo. In this context, it might be known as a process that articulates teaching and research to enable the transforming action between the University and society. In this way, it enriches the educational process by encouraging the socialization of academic knowledge and establishing a dynamic which contributes to the community's participation in university life. Due to the importance of the culture and university extension works which were conducted by the University of São Paulo and the need to review the concept of university extension activities used till now by the University,

\section{Vinicius Pedrazzi}

Universidade de São Paulo. Faculdade de Odontologia de Ribeirão Preto, São Paulo, Brasil

\section{Marina Mitiyo}

\section{YАMАMOTO}

Universidade de São Paulo. Faculdade de Economia, Administração e Contabilidade, São Paulo, Brasil 
changes were made in order to define the activities of culture and extension foreseen in the Statute and the General Regiment of the University of São Paulo. It is to enhance the cultural and extension activities in the evaluation of professors, students and university staff, even to encourage the establishment of criteria for the evaluation of university extension activities. To be able to achieve the desired purpose, it is necessary the inseparable articulation between teaching, research and extension activities and the culture produced in the academy, and the externalization of the results in favor of benefits to society.

Keywords: Culture. Extension. Articulated actions.

\section{INTRODUÇÃO}

\section{A valorização em igual par entre as atividades-fim da Universidade de São}

Paulo, onde se dê mesma valia para o ensino, para a pesquisa e para a extensão, tem sido uma luta árdua que se mistura com a própria origem da Universidade.

Em sua "Carta de São Paulo: políticas públicas de cultura e extensão universitária”, a Profa. Dra. Maria Arminda do Nascimento Arruda, Pró-Reitora de Cultura e Extensão Universitária da USP, levanta uma interessantíssima questão: a USP, comparada às coirmãs distribuídas em todo território nacional, apresenta uma característica que a distingue quando se trata de temas de cultura e de extensão universitária, pois ambas atividades são temas enlaçados que merecem mesmo peso e valor em uma mesma Pró-reitoria [1].

Ainda nesse documento, exarado após aprovação em plenária no enceramento do ProExt Cultura-SP, no auditório da Faculdade de Economia, Administração e Contabilidade da Universidade de São Paulo, em 2010, há uma perfeita construção a respeito de cultura e extensão, e sua articulação entre a Academia e a Sociedade:

A área da cultura e da extensão deve se orientar, em suma, por uma visão pública das atividades que implementa, resguardando-se, todavia, das apropriações circunstanciais de suas ações. Por se tratar de instituições públicas, as universidades estão envolvidas por compromissos republicanos. A condição mesma desse exercício é a de se construir pontes com a sociedade que não suprimam a essência de sua identidade formada no axioma do conhecimento, sem o qual as ações extrovertidas não se diferenciariam de todas as outras que pululam nas sociedades contemporâneas e se perderiam em meio a inúmeras iniciativas aparentemente assemelhadas. Por fim, a universidade não cumpriria o papel de formar cidadãos para o mundo em movimento, caso não democratize e difunda o acesso à cultura, êmulo da ultrapassagem das profundas desigualdades sociais[1].

Tal qual para atividades específicas de ensino e de pesquisa, a manifestação e a extrapolação das atividades de Cultura e Extensão ocorrem por meio da elaboração de Projetos.

Projetos de Extensão (ou culturais, ou envolvendo ambas as atividades) são textos analíticos resultantes de estudos e revisões ou de experiências desenvolvidas nas áreas temáticas estabelecidas para a cultura e para a extensão universitária, a saber:

1. Comunicação;

2. Cultura;

3. Direitos Humanos; 
4. Educação;

5. Meio Ambiente;

6. Saúde;

7. Tecnologia e Trabalho.

Assim, para que sejam alcançadas as atividades almejadas, se faz mister a elaboração de um projeto de extensão completo, que preveja itens inerentes às atividades propostas; bem como é altamente salutar a articulação entre atividades de ensino, de pesquisa e de extensão, que pode até prever a assistência à sociedade. Também a interdisciplinaridade em suas distintas emanações é muito incentivada e valorizada.

Para que se desenvolvam ações articuladas na extensão, deve-se iniciar, portanto, com um planejamento (planejar o projeto), e é preciso haver, necessariamente, um perfeito engajamento entre o líder e a equipe.

Em se tratando de planejamento estratégico, a Figura 1 apresenta um bom exemplo de fluxograma denominado "Hélice Tripla" que, citando Ribeiro (2010), "o tripé, que une a articulação entre governo e setor privado, com forte presença da academia (negrito do autor), se estabelece cada vez mais como motor para o desenvolvimento econômico e social" [2].

Note-se aqui o centro de intersecção dos círculos, que coloca em evidência as pessoas e as ideias. E, no conceito de atividades de extensão, a maior valia é dada para a articulação entre a produção de conhecimento acadêmico (ideias) e a aplicação em benefício da sociedade (pessoas).

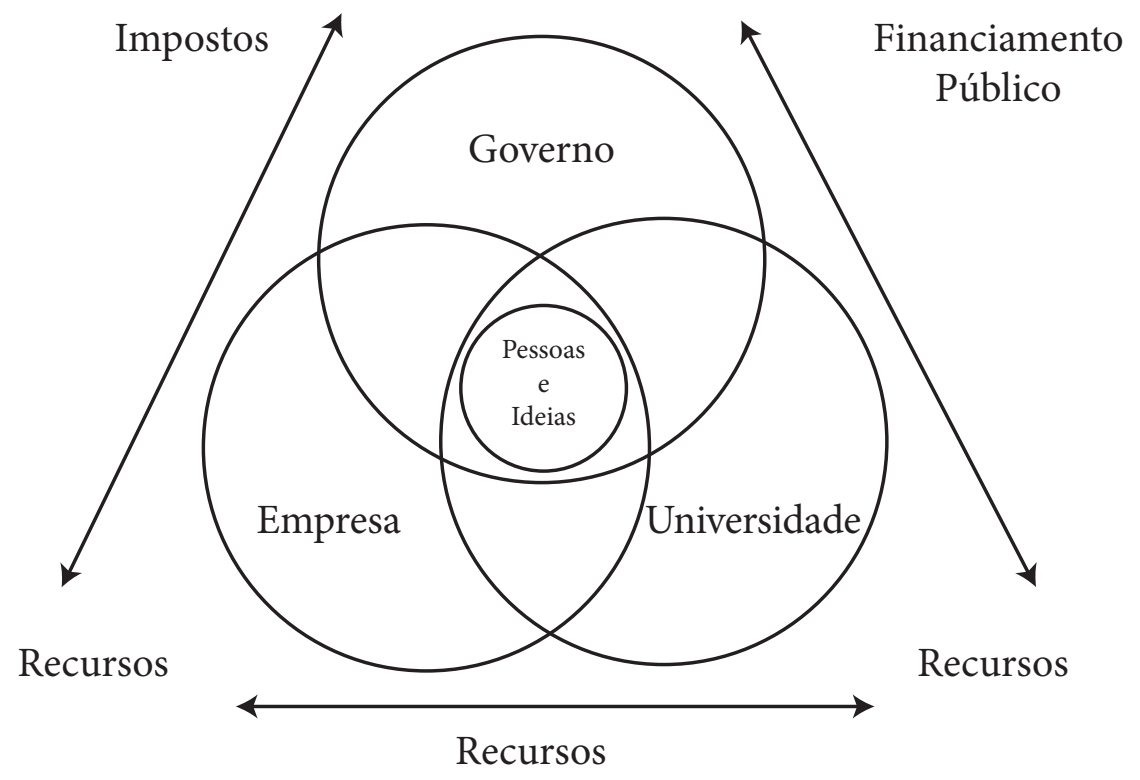

Figura 1 - Hélice tripla das ações articuladas (fomento e ação) 
Nesse contexto é de suma importância a obediência do binômio:

1. a responsabilidade de cada um e;

2. o comprometimento de todos.

Um projeto de extensão requer uma integração simbiótica ou de mutualismo para que possa atingir os melhores objetivos propostos. Isso é articulação.

Um bom exemplo de ações articuladas foi a realização do I Fórum de Integração dos Serviços de Saúde e das Atividades de Ensino, Pesquisa e Extensão da USP, realizado no Bloco Didático da Faculdade de Medicina de Ribeirão Preto da USP, nos dias 15 e 16 de março de 2011. O evento teve a finalidade de discutir as relações da universidade com os serviços de saúde, as fontes de fomento e os programas do Ministério da Saúde. Após receberem informações nas diversas palestras ministradas no primeiro dia do Fórum, os participantes foram distribuídos em cinco grupos multidisciplinares de discussão sob o tema: "Inserção, infraestrutura, recursos humanos e materiais e interdisciplinaridade nos serviços de saúde" [3].

No I Congresso Brasileiro de Extensão Universitária (2002), realizado em João Pessoa (PB) os participantes reafirmam o conceito de extensão como "O processo educativo, cultural e científico, que articula o ensino e a pesquisa de forma indissociável, viabiliza a relação transformadora entre a universidade e os demais segmentos da sociedade, trazendo para a universidade a pergunta sobre a relevância social da produção e socialização do conhecimento" [4].

O objetivo da elaboração deste artigo foi divulgar a palestra proferida pelos autores do artigo durante o $3^{\circ}$ Workshop de Agentes de Cultura e Extensão Universitária Diagnósticos e Perspectivas, realizado entre os dias 18 a 20 de junho, no Museu Republicano de Itu, ocasião em que se discutiu o impacto das políticas de incentivo à produção cultural na rotina universitária.

\section{MATERIAIS E MÉTODOS}

A Pró-reitora de Cultura e Extensão Universitária, Profa. Dra. Maria Arminda do Nascimento Arruda, ministrou a palestra inaugural abordando como o volume da produção de docentes da USP, no campo da cultura e da extensão, é revertida em publicações, participações em eventos acadêmicos e, principalmente, como isso é percebido e valorizado pela comunidade uspiana.

O Workshop de Agentes de Cultura e Extensão Universitária foi organizado pela primeira vez em 2008, com o objetivo de aprimorar o processo de divulgação do acervo cultural da Universidade e ampliar a interação entre os agentes que atuam nessa área. Para reforçar esse objetivo, este evento é organizado em espaços da USP normalmente desconhecidos da comunidade universitária. $\mathrm{O}$ evento foi transmitido simultaneamente pelo IPTV e a programação pode ser acessada em: <http:/ /www.prceu.usp.br/eventos/ workshopagentes2013.php>.

A palestra foi desenvolvida a convite da Comissão Organizadora do Evento, pelos 
autores deste artigo, sendo ministrada no dia 18 de junho de 2013, e teve como objetivo demonstrar e discutir a importância das ações articuladas entre ensino, pesquisa e extensão, por meio do desenvolvimento de projetos de cultura e extensão dentro dos programas perenes e também naqueles eventuais e Editais Especiais da Pró-Reitora de Cultura e Extensão Universitária. Após a palestra, os docentes dialogaram com os ouvintes respondendo a várias dúvidas e questionamentos.

\section{RESULTADOS}

A diferenciação de projetos de pesquisa (puros) daqueles de cultura e extensão foi abordada, bem como explicitados os itens constantes, objetivos, metas, público-alvo e benefícios para a implantação correta dos projetos almejados.

Foram apresentados brevemente cada um dos programas estáveis da PRCEU, como:

" Aprender com Cultura e Extensão

" A USP e as Profissões

" Editais Especiais

" Comissão de Estudos de Problemas Ambientais

" Giro Cultural USP

" Nascente

" Fomento às Iniciativas de Cultura e Extensão

" Caminhos da Cultura

" Núcleo dos Direitos, com subprogramas:

" Aproxima-Ação

» ITCP-USP

" Núcleo de Excelência pela Primeira Infância

" Universidade Aberta à Terceira Idade

" USP Diversidade

" USP Legal

Os programas de Extensão visam integrar projetos universitários com as necessidades da comunidade em que estão inseridos e têm caráter de continuidade. Foi citado como exemplo: projeto de ginástica laboral com música na associação de moradores de uma comunidade. Os atores do projeto tanto podem operar, aplicando os conceitos diretamente na comunidade, quanto formando agentes comunitários multiplicadores da ação, com apoio da Prefeitura ou ACI, para atender trabalhadores que vivem próximos à universidade ou faculdade.

A articulação é importantíssima na ação formadora direta, individual ou em massa, e na formação de células disseminadoras dos conhecimentos aprendidos para as diversas comunidades. A socialização do conhecimento é uma das formas mais democráticas para o desenvolvimento de uma Nação soberana.

Foi apresentado também um quadro sinótico na forma de fluxograma para que os ouvintes pudessem se inteirar da sistemática de funcionamento da Pró-Reitoria de Cultura e Extensão dentro do organograma da USP (Figura 2). 
Figura 2 - Organograma simplificado de atuação da PRCEU na atenção às atividades de Cultura e Extensão

\section{Universidade de São Paulo \\ 1 \\ Reitoria de USP -RUSP \\ 1}

Pró-Reitoria de Cultura e Extensão Universitáia -PRCEU

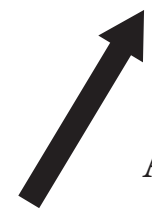

Câmera de Ação Cultural e de Extensão Universitária Câmera de Cursos

Câmera de Formação Profissional Comitê de Fomento

Comissão de Cultura e Extensão Universitária

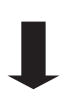

Ações Articuladas
Pró-Reitor

Adjunto Cultura

Assessores Técnicos de Gabinete Assistentes Técnicos do Gabinete Chefes de Divisão

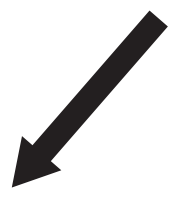

Grupo Coordenador das Atividades de Cultura e

Extensão Universitária do Campus de Ribeirão Preto

Pedrazzi, 2013

\section{DISCUSSÃO}

O sucesso das ações articuladas na Cultura e Extensão está diretamente relacionado e comprometido com a elaboração e apresentação de Projetos de Extensão. Estes são, via de regra, articulações concretas de conhecimentos oriundos de ensino e/ou pesquisa aplicados em atividades que possam gerar ações transformadoras em uma comunidade, seja ela interna ou externa à Universidade de São Paulo.

Um bom exemplo de ações articuladas na Cultura e Extensão foi a criação, pela Resolução CoCEx 5.174, de 3 de fevereiro de 2005, do Grupo Coordenador das Atividades de Cultura e Extensão Universitária do Campus de Ribeirão Preto da Universidade de São Paulo. Composto por um presidente e um vice-presidente, eleitos pelos pares, que são presidentes das Comissões de Cultura e Extensão das unidades do campus de Ribeirão Preto, possui representantes discentes (um aluno de graduação e um de Pós-Graduação), dois representantes da Prefeitura do Campus de Ribeirão Preto e um representante da Secretaria de Educação e Cultura da Prefeitura Municipal de Ribeirão Preto.

O Grupo coordenador tem as funções precípuas de fomentar a política de ação cultural e extensão universitária para uso qualificado do campus de Ribeirão Preto, promover o desenvolvimento de ações culturais e de extensão universitária interunidades no campus (articulação e interdisciplinaridade) e aprovar e supervisionar a execução dos projetos e das atividades culturais do campus.

Os projetos de extensão devem apresentar algumas características para a sua 
implementação e obtenção de melhores resultados. Devem, além da natureza acadêmica, cumprir ao preceito da articulação entre ensino, pesquisa e extensão (com integração da atividade de extensão desenvolvida à formação técnica e cidadã do estudante e pela produção e difusão de novos conhecimentos, novas técnicas e novas metodologias); ter, sempre que possível, características de interdisciplinaridade, pela interação de modelos e conceitos complementares, de material analítico e de metodologia, com ações interprofissionais e interinstitucionais, apresentando consistência teórica e operacional que permitam a viabilização das atividades de extensão.

É salutar ainda que as atividades de extensão gerem impacto positivo na formação técnico-científica, pessoal e social com a atribuição de créditos acadêmicos, sob orientação ou tutoria docente e a avaliação do estudante, bem como a geração de produtos ou processos, como publicações, monografias, dissertações, teses, abertura de novas linhas de extensão, ensino e pesquisa.

A existência no projeto/programa de ações articuladas envolvendo atuação na educação (Educação de Jovens e Adultos, Formação de Professores, Educação Ambiental, etc.), bem como a sua relação com a sociedade, o impacto social - pela ação transformadora sobre os problemas sociais, contribuição à inclusão de grupos sociais, ao desenvolvimento de meios e processos de produção, inovação e transferência de conhecimento e a ampliação de oportunidades educacionais - facilita o acesso ao processo de formação e de qualificação.

Deseja-se, também, estabelecer relação bilateral com os outros setores da sociedade, pela interação do conhecimento e experiência acumulados na academia com o saber popular e pela articulação com organizações intra e extramuros, objetivando o desenvolvimento de sistemas de parcerias interinstitucionais (interdisciplinaridade - trans, pluri, multi). Assim, objetiva-se a contribuição na formulação, implementação e acompanhamento das políticas públicas prioritárias ao desenvolvimento regional e nacional.

É importante que, durante todo o processo, desde a sua aprovação e implementação, haja uma estrutura bem definida para o monitoramento, acompanhamento e avaliação do projeto e de suas ações transformadoras. A partir da análise dos resultados alcançados, caberá ao comitê gestor deliberar pela sobrevivência, reapresentação, cancelamento ou mesmo perenidade do mesmo, que poderá transformá-lo em um programa!

\section{CONCLUSÕES}

Projetos de Extensão são textos analíticos resultantes de estudos e revisões sobre temas relacionados à extensão universitária ou de experiências desenvolvidas nas áreas temáticas estabelecidas para a extensão universitária, a saber:

1. Comunicação;

2. Cultura;

3. Direitos Humanos;

4. Educação;

5. Meio Ambiente; 
6. Saúde;

7. Tecnologia e Trabalho.

Os programas de Extensão visam integrar projetos universitários com as necessidades da comunidade em que estão inseridos e têm caráter de continuidade. Os atores do projeto podem tanto operar aplicando os conceitos diretamente na comunidade, quanto formar agentes comunitários multiplicadores da ação, com apoio da Administração ou Prefeitura, para atender trabalhadores que vivem próximos à universidade ou faculdade.

\section{REFERÊNCIAS}

[1] ARRUDA, M. A. N. Carta de São Paulo: políticas públicas de cultura e extensão universitária. 2010. Disponível em: <http://www.prceu.usp.br/eventos/ proext/cartasp.pdf $>$. Acessado em: 09 set. 2013.

[2] RIBEIRO, C. Inovabrasil. FINEP. Brasília, 2010. Disponível em: <http://inovabrasil.blogspot.com.br/2010/o9/helice-tripla-acoes-articuladas-dao.html $>$ Acesso em: 17 set. 2013.

[3] SAWADA, N. O.; PEDRAZZI, V.; RODRIGUES, M. L. V. I Fórum de Integração dos Serviços de Saúde e das Atividades de Ensino, Pesquisa e Extensão da USP. Revista de Cultura e Extensão USP, Brasil, v. 6, p. 33-40, out. 2011. ISSN 2316-906o. Disponível em: <http://www.revistas.usp.br/rce/article/view/532>. Acesso em: o1 Nov. 2013. doi:10.116o6/issn.2316-906o.v6iop33-40.

[4] CONGRESSO BRASILEIRO DE EXTENSÃO UNIVERSITÁRIA, 1, 2002. (Anais). João Pessoa, 2002. Disponível em: <http://www.prac.ufpb.br/anais/ Icbeu_anais/anais/ficha.html>. Acesso em: 16 set. 2010.

VINICIUS PEDRAZZI professor associado 3 do Departamento de Materiais Dentários e Prótese da Faculdade de Odontologia de Ribeirão Preto da Universidade de São Paulo e Coordenador da Câmara de Ação Cultural e de Extensão Universitária - e-mail: pedrazzi@forp.usp.br

MARINA MITIYO YAMAMOTO professora associada da Faculdade de Economia, Administração e Contabilidade da Universidade de São Paulo e Pró-Reitora Adjunta de Cultura da Pró-Reitoria de Cultura e Extensão Universitária da Universidade de São Paulo 